\title{
Call of Duty: The Emotional and Psychosocial Lived Experience of Eldest Child towards Parental Death
}

\author{
Marica G. Estrada, RN, MAN, Ph.D, ${ }^{1}$ Christopher Joseph P. Serrano ${ }^{1, *}$, Kristian Hero \\ G. Serrano ${ }^{1}$, Francis Victor C. Setias ${ }^{1}$, Kim Z. Sia ${ }^{1}$, Hazel Joyce A. Sigua ${ }^{1}$, Pauline \\ Denise P. Tecson ${ }^{1}$, La Arnie M. Lazalita, RN, MAN ${ }^{1}$ \\ ${ }^{1}$ College of Nursing, University of Santo Tomas, \\ España Boulevard, Manila, Philippines 1015 \\ estradamarica@yahoo.com
}

\begin{abstract}
:
Aim: Death is a natural part of life; not only does this imply the inevitability that people will pass away, but also the emotional compromise of the bereaved. Numerous literatures have shown the intense grief and devastation of the parents upon losing their child, however, availability of literatures regarding lived experiences by the eldest child who experienced parental death is limited. This gap in knowledge led us to conduct this phenomenological study that will unravel the essence behind the experiences of the eldest child who experienced parental death.
\end{abstract}

Methods: A descriptive phenomenological study was conducted involving a total of 5 handpicked participants. A semi-structured interview was done, recorded and transcribed verbatim including non-verbal cues and clues. Following Colaizzi's method, we extracted participant's significant statements and organized the formalized meanings into clusters of themes.

Results: The phenomenon "Call of Duty" was materialized in this study which describes the eldest child's experiences of parental death. Three emerge themes were identified that clearly explains the eldest child's experience towards the demise of their parent. First, protected by the safe haven characterized the participants' reliance to their parent before the death occurs. Second, skirmished with parental loss highlighted their painful experiences of death and grieving. Lastly, armored to face the future captured the participants' struggle after the loss; positivism dominated amidst difficulties.

Conclusions: The essence of the eldest child's responses reflected the phenomenon "Call of Duty", captured on a military theme that described their lived experiences towards parental death. The participants' experiences of parental death had led them to the development of emotional and psychosocial maturity.

Keywords: Call of Duty, Eldest Child, Parent, Death, Lived Experience

\section{INTRODUCTION}

Death is a natural part of life; not only does this imply the inevitability that people will pass away, but also the emotional compromise of the bereaved especially if the deceased is extremely significant to them. Every day, it is estimated that 8 out of 1, 000 people die worldwide (Harvest Fields Index, 2013) while in the Philippines, there is an estimated death of 5 out of 1,000 residents (CIA World Factbook, 2013). Ignoring the harsh reality of a loss is referred to as death denial; this strategy is used to elude uneasiness about death (Aries, 1981). However, denial incapacitates the development of personal and social resources which aids both men and women in coping with death. (Corn, 2009).

Numerous literatures have shown the intense grief and devastation of the parents (Fletcher, 2002; Sanders, 1979), poor psychological and physical health (Rogers, Floyd, Seltzer, Greenberg, \& Hong, 2008), and high rates of both natural and non-natural death (e.g. suicide) (Rostila, Saarela, \& Kawachi, 2012) upon losing their child. This particular loss adversely affects multiple domains of parental wellbeing, including health and marital quality (Bolton, Au, Leslie, Martens, Enns, \& Roos, 2013). Compared with the non-bereaved parents, those who are bereaved report poorer marital quality and are more likely to divorce (Najman et.al., 1993), have suicidal ideations and may follow through with this in conjunction with advanced mortality rates. (Murphy, Tapper, Johnson, \& Lohan, 2003; 
Chen, Kuo, Wu, \& Yang, 2012; Li, Precht, Mortensen, \& Olsen, 2003; Rostila et al., 2012). Li, Laursen, Precht, Olsen, \& Mortensen (2005) study has shown that parents who experienced death of a child had a higher risk of a first-time hospitalization for a psychiatric disorder. Other works have centered on the relationship between parental bereavement and incidence of cancer ( $\mathrm{Li}$, Johansen \& Olsen 2002; and Li, Johansen, Hansen, \& Olsen 2003a). The results highlighted an increased risk for cancer in bereaved mothers possibly precipitated by stress-induced adverse lifestyle changes. The feeling of loss may never dissipate, threatening the parents' wellbeing for decades, long after the death of their child (Rogers et. al., 2008). A study by Jordan, Parkes, Price, \& Prior (2011) made used the term "preserving" which means that the feeling of loss will always be present regardless whether the parent has had closure and he or she has moved on in life without their child, thus continuing the parental responsibilities even after the death of the child.

Those who are more in need of support are the young adults' family members, aged $18-24$ (Brown \& Jekielek, 2005). Nazarene.org (2013) defined young adults as those who are in their higher education years, starting their career, and etc. In Erik Erickson's developmental theory, this comprises the ages of an adolescents, $18-19$, and the early 20's. Research demonstrates a clear link between stressors and adolescent internalizing and externalizing symptomatology. (Grant, Compas, Stuhlmacher, McMahon, \& Halpern, 2003; Mash \& Barkley, 2003). Adolescence is a period of inherent vulnerability. This is the phase wherein they start to set up and establish meaningful and satisfying relationships among peers without feeling any inhibitions. In this stage, they also acquire a sense of purpose and a sentiment of maturity about themselves. Parents should recognize changes that their child is undergoing as they should avoid any unnecessary detachments in their support for the child to avoid strain in the parent-child relationship (Kliegman, Behrman, Jenson, \& Stanton, 2011). In addition, during the early stages of adulthood (early 20's), most bodily systems have already fully developed, such as application skills and use of knowledge through analytical capabilities; such is the need to discuss stressful life events with them. By failing to meet this developmental stage, significant life events may become stressors to the individual, leading to anxiety and formation of improper coping mechanisms that would eventually result in mental illness (Keltner et. al, 2007). In terms of understanding death, adolescents can be difficult to deal with, the unfairness of death and existential outlook on life's meaning may alter grieving in a variety of ways, such as withdrawing from the family and seeking support from their peers instead, and/or be involved in immoral activities such as drugs and alcohol drinking. Hence, loss may take them to a journey towards self-improvement and development where one can increase their abilities as a person. They find themselves taking charge of new family roles and responsibilities (Dowdney, 2008).

The availability of literatures pertaining to the lived experiences of the eldest child with regard to parental death is currently limited in the Philippines. This gap in knowledge led the researchers to conduct this phenomenological study that will unravel the essence behind the experiences of parental death to young adult who are in their college years and who are the eldest amongst their siblings.

The researchers intended to enhance nursing knowledge regarding the lived experience of the eldest child specifically the emotional and psychosocial aspects after parental death which shall serve as a reference for future related studies. In lieu of the aforementioned, an increased knowledge shall consequently invoke awareness that will make the nurses to be more empathic in their delivery of appropriate interventions such as counseling or group therapy.

\section{Research Question}

The study aims to unravel the essence of the eldest child towards parental death. Answers on the central question will be sought by the researchers:

"What describes the lived experience, specifically emotional and psychosocial aspect, of the eldest child towards parental death?"

\section{METHODS}

\subsection{Research Design}

This study's construct used a phenomenological qualitative design in an attempt to extract an understanding of the experiences of the eldest child towards parental death. Phenomenology is concerned with the lived experiences of people- an approach to understanding the meaning of life experience of people (Rossman \& Rallis, 1998, Polit \& Beck, 2008; Bawalan, 2012; Waters, 2014). 
Creswell (2009) defined phenomenology as a research strategy of inquiry in which the researcher identifies the essence of human experiences about a phenomenon as described by participants" It answers the question, "What is the meaning of one's phenomena?" and its major concern of phenomenological analysis is to understand "how the everyday, inter-subjective world is constituted" (Schwandt, 2000; Burns \& Grove, 2013).

According to Groenewald (2004), "The operative word in phenomenological research is described. The aim of the researcher is to describe as accurately as possible the phenomenon, refraining from any pre-given framework, but remaining true to the facts. The phenomenologist is concerned with understanding social and psychological phenomena from the perspectives of people involved". Interviews can be used in phenomenological research. This research used this method to address the research question.

\subsection{Selection}

\begin{tabular}{|l|l|l|l|l|l|l|}
\hline $\begin{array}{l}\text { Code } \\
\text { Names }\end{array}$ & Age & Gender & Civil Status & Citizenship & Religion & $\begin{array}{l}\text { Deceased } \\
\text { Parent }\end{array}$ \\
\hline Alpha & 19 & M & Single & Filipino & Christian & Mother \\
\hline Bravo & 18 & F & Single & Filipino & Roman Catholic & Father \\
\hline Charlie & 19 & F & Single & Filipino & Roman Catholic & Father \\
\hline Delta & 21 & M & Single & Filipino & Christian & Father \\
\hline Echo & 20 & F & Single & Filipino & Roman Catholic & Mother \\
\hline
\end{tabular}

Five participants who are residing near Manila were chosen using non - probability purposive sampling technique. Samples will be taken by the researchers based on the eligibility criteria including the ability and voluntariness or the participants to contribute in this research (Oliver, 2006). An inclusion criterion was imposed on the recruitment for the sample. The participants comprised of the following: either mother or father who has been deceased for about 6 months -3 years as Keltner (2007) stated that the grieving process usually lasts for about 6 months. The researchers decided to include this criterion so that the possibility of emotional harm during the interview is kept to a minimal; eldest child in the family: aged $18-21$ years old; has passed their respective university's psychological test and is currently enrolled. The sample size was determined by data saturation point as the basis for discontinuation of recruitment. The saturation point is defined as the gathering of information to the point where a sense of closure is achieved as new data produces similar results (Polit \& Beck, 2008; Manson, 2010). Upon attainment of the saturation point, an additional two participants were included during the collection and analysis of information to ensure consistency of the findings.

\subsection{Procedures}

An interview guide was utilized which consists of a 2-part instrument. This includes the robotfoto with demographic profiles of the participants following an in-depth interview using open-ended questions to discover and encompass in its totality. The interview guide underwent constant analysis and evaluation by experts in the field of psychiatric nursing and qualitative study to achieve credibility. The researchers then proceeded to contact the willing participants ages $18-21$ years old to secure from them an informed consent. The objectives, risk and benefits were included in the consent forms which were given to the participants. Interviews were scheduled at the participants' availability and convenience. Incidentally, the interviews were all held in a coffee shop as with all the participants' preference. The interviewee had the option to bring a companion during the interview to make them feel comfortable in sharing their experience towards parental death. Prior to the actual interview with the participants, self-awareness was done by us with the aid of Johari's Window. It was facilitated by the research adviser to be able to avoid bias and counter-transference which could alter the results of the study. Beforehand, the researchers conducted a mock interview with ourselves as part of the training process. An informed consent was given to a participant prior to the interview. This participant was excluded from the study. The two researchers were assigned for the interview: one would ask the questions, while the other would record the interview and take notes including verbal and non-verbal form of communication. To maintain consistency in the delivery of the interview, only one researcher was assigned to be the interviewer for every respondent. The whole process of mock interview was video recorded and later presented to the expert for an evaluation of the interview conducted. Subsequently, the expert advised the researchers to proceed with the data gathering. The researchers contacted the participants a week before the set date of the interview. An 
informal conversation was done also prior to the actual interview process. After establishing rapport, the participants began sharing their experiences which was guided by the central question: "What describes the lived experience, specifically emotional and psychosocial aspect, of the eldest child towards parental death?" Follow up questions were asked to seek clarification. If the participants defer to answer certain questions, they may do so. The interviewer administered debriefing after the interview by diverting the topic into a less sensitive subject. This was done to ensure that no emotional harm was imposed during the interview. In case of emotional breakdown during the interview process the participants will be referred to a guidance counselor to address their psychological needs. The audio recorded interviews and written notes were labeled according to the participants' pseudonyms to ensure their anonymity and maintain confidentiality. The data gathered were transcribed exactly based on what the participants have stated to maintain uniformity.

\subsection{Mode of Analysis}

The Colaizzi's method (1978) was vital in analyzing the data in this research. Audio recorded interviews were transcribed through separate verbatim accounts to reduce any text inaccuracy by us. Spot checking of the verbatim reports were done to guarantee that the audio recorded interviews were being transcribed word per word. Each transcription was examined and re-read to attain a wholesome understanding of the content. All biases and prejudices concerning the phenomenon were avoided during every analysis (Creswell, 2003). The noteworthy testimonial regarding the phenomenon was extracted and these data were documented on a separate sheet. Afterwards, the gists of these important data were classified into categories (cool analysis) and clusters of themes (warm analysis). A rich description was created after gathering the significant findings of the study. Researchers sought consult from experts who reviewed the findings in terms of richness and the totality of the content to validate and provide sufficient description. The fundamental structure of the information was expressed additionally. This aided in the reduction of findings which are redundant, misused or overestimated in terms of descriptions so an overall structure was formed on this study. Finally, establishing the truthfulness and trustworthiness of the information gathered was done by the use of member checking; a technique wherein the results were given back to the participants and together with the researchers, discuss the collected data with them to further authenticate the information (Shosha, 2012).

\subsection{Rigor of the Study}

To ensure the trustworthiness of the study, the researchers made sure to project the principles of credibility, dependability, confirmability and transferability. Credibility, as viewed by Lincoln and Guba (1985), is an overriding goal of qualitative research. The researchers have all experienced death of close relatives such as the death of grandparents, aunt, and the like. However, the researchers have not experience parental death, except for one who was not eligible to interview participants. Therefore, this did not affect the credibility of the result of the study. Also, to ensure credibility in the study, validation of the interview guide to the 3 experts, and the use of bracketing method to remove preconceived ideas towards parental death were observed. Bracketing is where the researchers defined death in general among themselves and shared their insights towards this. According to Creswell (2003), member checking is another way of confirming the credibility of the findings. Member checking was done by validating the findings of the study with the participants, allowing them to comment on the emerging interpretations. On the other hand, the principle of dependability or stability over time was achieved through the involvement of the experts in the field of the psychiatry, who validated the study. The criterion of confirmability or objectivity was addressed by excluding biases, including the researcher's own opinions or perceptions during the data gathering. As a proof of their objectivity, the researchers have encoded the verbatim accounts of the participants. In accomplishing the principle of transferability, the researchers included rich descriptions in depicting the results and discussion of the study to make the study suitable to other settings.

\subsection{Ethical Considerations}

With regard to certain ethical issues that might arise from exploring the eldest child's perception towards parental death; debriefing was administered as a requirement for every participant. In case of emotional breakdown, participants will be referred to the guidance counselor. It is here that they will be comforted, and consequently, be given an opportunity to address any psychological implications that they might have incurred during the interview process. Due to the critical issues surrounding the 
subject matter, both the principles of beneficence and non-maleficence were maintained through the observance of sensitivity during the interview. The researchers, in response to the application of justice, avoided any kind of prejudice among the participants through the exclusion of gender, race, and ethnicity from the inclusion criteria. To promote the exercise of their autonomy, informed consents were secured from each respondent, and their decision to revoke participation in the study at any point if they so desire was respected. The actual names of the participants were concealed by pseudonyms to protect the individual against any form of exploit. This was also done to guarantee confidentiality of the person's identity. Participants were assured that the information gathered during interviews would not be divulged to other people and was not be used for any purposes outside of this study. In addition, all recorded interviews via audio recorder and written data were labeled according to their pseudonyms and archived in a secure location.

\section{Results}

After gathering data from the participants, the researchers decided to use phrases that are military in nature in line with the theme of this study and with their experiences. They have described the event as a battle they never expected having.

\section{Protected by the Safe Haven}

The 1st emerging theme that surfaced in the study was PROTECTED BY THE SAFE HAVEN characterized by being unable to function as a whole due to the need of a parental role. For the participants, protected by the safe haven is the act of the parental figure in providing care for the growth of the participants. This leads to the participants being dependent on them for the essentials of daily living be it material or for moral support. Under this theme, 2 subthemes were evident: Freedom from Worries and Dependence. This subtheme displays the attitude of the eldest child towards responsibility during the presence of their deceased parent. The participants had little concern with present and future responsibilities of being the eldest in the household.

\section{Freedom from Worries}

Some of the participants stated that in their everyday lives, one way or another, they were reliant on their parent. They leave all the decision making to their parents, disregarding their role as an eldest child and are generally unconcerned about the future. Even though they are the eldest, they have the same mindset about responsibilities akin to their younger siblings. This was verified by the following statements:

"I ask my mom to wake me up especially when I stayed up late from last night." - ALPHA

"Before, I was a happy-go-lucky person. I hang out a lot with my friends and I am a computer addict. If I want something, I'll do it. I do not have a sense of responsibility. I don't have any goals in life; I was not serious about anything because I know we have the funds, daddy's there, someone will take care of us". -DELTA

"My mom is really glued to me, like she is always tailing me going to and from places with me because I am her only child. She really keeps tabs on me so wherever I go, she goes; when I go with my friends she also tags along." -ECHO

\section{Dependence}

In the course of the interview, the participants elaborated on their relationships with their parent before the death occurred. All of them stated that they were reliant on their parent in the preparation of food, cleaning the house, and various household chores. It was as manifested by the following verbalizations:

"Every Monday morning, he accompanies me to the school, already carrying my washed clothes. He does it every week without fail... Since we don't have helpers in our house, my father usually does the household chores when my mom has work. "-BRAVO CHARLIE.

"When I wake up in the morning, my father prepares our breakfast and food for school "-

\section{Skirmished with Parental Loss}

SKIRMISHED WITH PARENTAL LOSS is the 2nd theme emerging from this study. The word 'skirmish' is defined as a brief and usually unplanned fight during a war (Merriam-Webster, 2014). A 
sudden change in the participants' normal routine after the loss of the parental figure has caused them to be anxious of the moment and made them be unsure of their future. There were 3 subthemes that were categorized under this: (1) Shell shocked, (2) Combat fatigue, and (3) Dithered Moments. The participants verbalized that they were in a state of uncertainty on whether or not to believe that they are about to lose the ones they love. Hence, they were caught up in their emotions which caused them to worry about the events that have transpired and what will happen to them and their family in the future.

\section{Shell Shocked}

'Shell shock' was first used during the First World War by the British doctors (Simkin, 1997; 2014). This term is now commonly known as "Post-traumatic Distress Syndrome." We made use of this phrase to describe the anticipated event that happened to the participants.

The participants were caught off guard during the death of their parent, and which they became perplexed. The participants verbalized that they were in a state of disbelief upon discovery of the impending death of their parent. This led them to develop a feeling of numbness and uncertainty. This was verified by the following statements:

"I felt that I was not my own self during that time since I don't know what was happening. ALPHA

"I am confused. I don't know what was happening. Why my grandmother told that to my mom and why they are not telling me anything about what happened." - CHARLIE

"I did not know. Only my mommy knows. I was actually surprised. My mom asked to accompany her to get something at the Pier since I know how to drive during that time. When I was going down on the elevator, there she told me about the daddy's condition. I froze. The whole day was blankly staring out of nowhere. I have no idea if it's true or not. I don't know what to do" - DELTA

This sense of confusion may also be the result of the lack of knowledge with regard to the situation or from the development of events. This was evidenced by:

"The first thing they checked was the BP, and then they said they would call the technician the one who would check the electrodes. In the back of my mind, I said, 'Do you really have to check the electrodes; my daddy isn't moving so there's no possibility that it would be misplaced.' Then the technician checked and said that it was okay. But the ECG was still fluctuating." - BRAVO

“...but on January when she went for her checkup and they found out she had water retention, we didn't know, what was it? Like she had water in her lungs? 'Okay, let's just have it removed!' But it actually meant that the cancer has metastasized, which means that the cancer is at its end stage, we didn't know so we resumed our normal daily routine." - ECHO

\section{Combat Fatigue}

The term 'Combat fatigue' refers to the participants feeling of grief. Sometime after the World War II, this term was used to define the stress and exhaustion felt by the militant during the war (Marlowe, 2000). Upon realization that they were about to lose someone precious, feelings of weariness and sadness suddenly welled up within them. As much as they wanted to maintain their composure, they were unable to for the reason that it has been too burdensome. The initial reaction was of letting their feelings out; it is evident in the gathered testimonies during the interview process; it may be through crying, anger, or a sentiment of wretchedness.

"I texted my mom, I asked her where dad is then she told me that he's already gone. When I received that text, I started to breakdown." - CHARLIE

"The moment when I was alone in the car, I started crying. My mom asked me to get something from the house and I was crying the whole time I was driving" - DELTA

"But after my mom got transferred to the ICU, I already said to myself that it was over. I began to accept it. When I felt here slipping away, I felt really sad." - ECHO

\section{Dithered Moments}

The participants shared their sentiments of being anxious of what was going on around them. 'Dither' means to delay taking an action because of uncertainty on what to do (Merriam-Webster, 
2014). They were eager to know what was transpiring yet afraid of what will happen. Upon finding out, they asked the question "What would happen to us now?" Their mother or father had been their source of strength and was a provider. The participants feared that they will lose everything alongside losing their parents. This event made them wary of the future as well; this was validated by the following responses:

"Different thoughts came into my mind such as 'What would happen to us? What would happen to my sister who is about to graduate from elementary and my youngest sister who is only three-years old?' I want her to see me graduate from college." - ALPHA

"I thought, 'What about us? What about our schooling, our business?' Our business was still starting in the construction field... 'What about my sisters? What about us, our daily necessities"' DELTA

As they were trying to determine what course of action to take, the tension of their worries and nervousness builds up. This was the moment where they would now ask themselves, "Should I continue to move forward or not?"

\section{Armored to Face the Future}

The 3rd emerging theme in the study was ARMORED TO FACE THE FUTURE. As evidenced by the participants' statements about their life after the death of their parents. Being armored to face the future is having the ability to overcome the challenges or stress brought about by the death experience. The participants were able to face this difficult experience and further transcend the internal and external conflicts surrounding him/her. Under this theme, 5 subthemes are evident: (1) Reinforcements (2) Promised Victory (3) Establishing Command, (4) Transcending the Negative, and (5) Honoring the Fallen. These subthemes describe the methods used by the participants to deal with this negative life experience. The presence of positive influences provided emotional support needed to guide and inspire them towards transcendence of difficulties encountered and will be encountered. They expected that things will go their way, that their personal life will remain positive. The participants considered the death experience as a challenge they needed to accept in order to become better individuals. Establishing command was the first step into maturity. This event created a driving force which prompted them into assuming the role left by the deceased parent. This experience provided them with insight towards the loss of their parent, a product of their struggle towards independence, a memento to honor those who have fallen.

\section{Reinforcement}

During military operations, reinforcements provide support to the primary forces. In this study, the participants identified the presence of their friends, relatives, religion and others as their support system. They would turn to their friends to share sentiments, and whose presence helped divert their attention. This kept them away from spiraling into a state of depression precipitated by the loss. The following statements support this:

"It was really a burden to the point that I uttered that I have gained all the problems in this world, but by the end of the day I would spend most of my time hanging out with my friends, share some of my sentiments and joke around with them - ALPHA

"Staying with friends, like when they're going to eat after class, I would join them even though I don't have enough money."- BRAVO

"We went to the chapel. I told my friends that I don't want to go home yet because I don't want to see him lying down without life so I'll stay here for a while"- CHARLIE

"Many have held on to me, my friends, my church leaders, many supported me. That time I felt everyone that loves daddy was there, so I was not depressed" - DELTA

"Actually, a major factor that I easily moved on is because of the support and comfort my friends gave me." - ECHO

Their extended family was able to console and help them to retain their sanity amidst the difficult situation they are in. This was evidenced by:

"We were really depressed due to the fact that our grandmother wasn't able to come; of course she's our emotional support." - BRAVO 
"When the time my aunties came, they were comforting my mom so I felt relieved somehow; at least we have support system, an extended family." - BRAVO

The participants affirmed themselves through their faith and sense of belongingness to their religion. Their fellow parishioner's willingness to listen and the advices they provided helped the participants accept the loss. This was substantiated by the following verbalization of the participants:

"I told myself that it happened for a certain reason. Even though it is difficult to accept I never blamed Him instead I thought that He has a plan for us. I regularly pray and attend Sunday services wherein I share some of my thoughts." - ALPHA

"I need to accept whatever happened. I was taught by my church leaders to be strong, 'Be a man' as they say. I need to stand up for my family now. I was not hurt at all, I don't know that feeling, but it was like you are happy for him. Because at least we know that he's in heaven and will not have a hard time anymore" - DELTA

One of the factors that helped one participant during times of emotional breakdown would be seeking advice from her friends and counselor. This was evidenced by:

"The night before my last make up duty, I was really stressed due to many requirements. I had my breakdown, this time I talked with my friend, I texted her first because I wasn't comfortable with my RLE. We texted from $7 \mathrm{pm}$ to $12 \mathrm{nn}$, she allowed me to verbalize all my feelings then gave me advice to handle it better." - BRAVO

"Actually, the guidance talked to me during our monthly grading period. I cried to her and that was the first time I tried reaching out because it's still counseling which after really felt good." BRAVO

\section{Promised Victory}

During the course of interview it was evident that the participants viewed the ordeal in a positive light. Even though it was arduous for them to accept parental death, they found solace in the belief that God had greater plans for them. This was evidenced by the following verbalizations:

"I told myself that it happened for a certain reason. Even though it is difficult to accept I never blamed Him instead I thought that He has a plan for us."- ALPHA

"I feel like he needs to go already. God has planned everything. Maybe this is the time where his pain and disease will be taken away from him and just rest in God's side." - CHARLIE

"I was not hurt at all, I don't know that feeling, but it was like you are happy for him. Because at least we know that he's in heaven and will not have a hard time anymore"- DELTA

\section{Establishing Command}

Despite the arduous experience of parental death, most of the participants viewed it as a challenge they needed to accept. They are preparing themselves for the responsibilities that they will soon take charge of, as a result of parental loss. For them, it opened another door, a door that sought to lead them into a brighter utopia. It was validated by the following statements:

"I thought of the incident during that time as like a challenge, so I was really challenged, I wasn't only the eldest that needs to be responsible, but I was the one to fill up what our daddy has left because it would be hard if only mommy will do it."- BRAVO

"I need to accept whatever happened. I was taught by my church leaders to be strong, 'Be a man' as they say. I need to stand up for my family now."- DELTA

"Now, I am thinking about the future; I am thinking about my sisters' future... So now, I promised myself that I want to give my family a better life, just like what daddy gave us before or maybe better."- DELTA

With the acceptance of a challenge comes a responsibility one may or may not be prepared for. An individual must possess both maturity and sensitivity in order to be aware and capable of taking charge. Likewise, the participants too heeded the call and have become aware of responsibilities, assuming roles left by their beloved parent. These were validated by the following verbalizations of the participants: 
"At first, I was the one who budgets our money before our aunt arrived. We made a decision to continue my studies here in Manila while my sisters will be transferred to the province." -ALPHA

"I had to face my fears of driving because I know it would be difficult for mom alone, that's why I tried to learn. Then for example it's 10 in the evening then mom would tell me "Your sister is having fever, go get some medicine in the pharmacy." Anything that mom would tell me to do, I would do it, I don't complain anymore because that's my role as the eldest, it's assumed already that anything mom gives I follow it." -BRAVO

"I became more mature and responsible to my family especially to my siblings. I became more aware of my responsibilities as the eldest child." -CHARLIE

"I took the responsibilities of the house such as maintenance of the things in the house and buying groceries and going to the market to buy ingredients, so my responsibility increased in a sense."-ECHO

\section{Transcending the Negative}

Most of the participants felt that even though they have experienced the immense heartache of losing a parent, they still remained positive. It was an experience that helped them handle the grieving process better. Instead of ruminating on what had transpired, they rechanneled their energy into a more fruitful pursuit such as improving their quality of life. This was evidenced by the following verbalizations:

"It was really a burden to the point that I already uttered that I gain all the problems, but by the end of the day I would spend most of my time hanging out with my friends, share some of my sentiments and joke around with them." - ALPHA

"Before it was my promise to my mom, then after a year, I met her in which she gave me more reason to live."- ALPHA

"I just cried heavily, heavier than my crying in the ER, heavier that the time of burial. My first breakdown was shaking, my hands were shaking. I tried comforting myself, so I calmed down. I just let my emotions come out. I didn't contain my feelings. Still life goes on. While crying I mumbled something, all I can remember is I mumbled that I miss him so much. Then after I felt good already, I went to continue on."// - BRAVO

"Grieving process has stages, right? You normally begin with denial, but don't stay there for too long. Don't stay on the negative side of death, but think that it happened for a reason. Just focus on the positive side that their parent is already in heaven. Move on. Life must go on."- CHARLIE

"It means that I should be strong, who else would be? As an eldest child, you should be strong for them to be their source of strength." -CHARLIE

\section{Honoring the Fallen}

Death of a loved one served as a learning experience to the participants. For them, it is the realization that life goes on even after the parent's death. Either one will strive to move on or be stuck in the past; fortunately the participants all have moved on and blossomed into mature young adults in spite of loss. This was evidenced by the following verbalizations:

"Don't think that you are the only one having a hard time instead consider the people around you that are also affected by the situation like your siblings and your mother or father. Also, reflect that if comforting them won't be coming from you, where would it come from? Always keep in mind that you should not become a burden to other people, instead you should be the one to step up and become their support" - ALPHA

"Take care of your family, you need to do what your mom does because you are the eldest, you will fill the vacancy so whatever task is given to you, do it. Your top priority is your family and you need to fulfill the tasks being the eldest." -BRAVO

"I became more mature and responsible to my family especially to my siblings. I became more aware of my responsibilities as the eldest child" -CHARLIE

"Grieving process has stages, right? You normally begin with denial, but don't stay there for too long. Don't stay on the negative side of death, but think that it happened for a reason. Just focus on the positive side that their parent is already in heaven. Move on. Life must go on. "-CHARLIE 
"Now, I am thinking about the future; I am thinking about my sisters' future... So now, I promised myself that I want to give my family a better life, just like what daddy gave us before or maybe better" -DELTA

"Those sweet moments, how much I love him. How much I appreciate him now. Now understand his situation when I was in his shoes and I appreciate him now." -DELTA

"My mom wanted me to take up accountancy, so I have to do well; it's more of my mindset. I perceive the death of my mom as a kind of motivation for me that I need to finish my college course with honors if possible for her, and to succeed in life so that she could see me." -ECHO

"My advice for those who is in the same situation as me is to make yourself not be too affected by the death of your mom because your mom wants to see you become successful so you must do good in whatever endeavor you are in as compared to withdrawing and doing nothing. So more on pushing forward"-ECHO

\section{DisCUSSION}

The study revolves around the phenomenon "Call of Duty". This phenomenon describes the unexpected battle of the eldest child with the death of the parent; a battle in which they overcome psychosocial and emotional struggles and achieving a mature outlook on life, taking on the role previously held by the deceased parent.

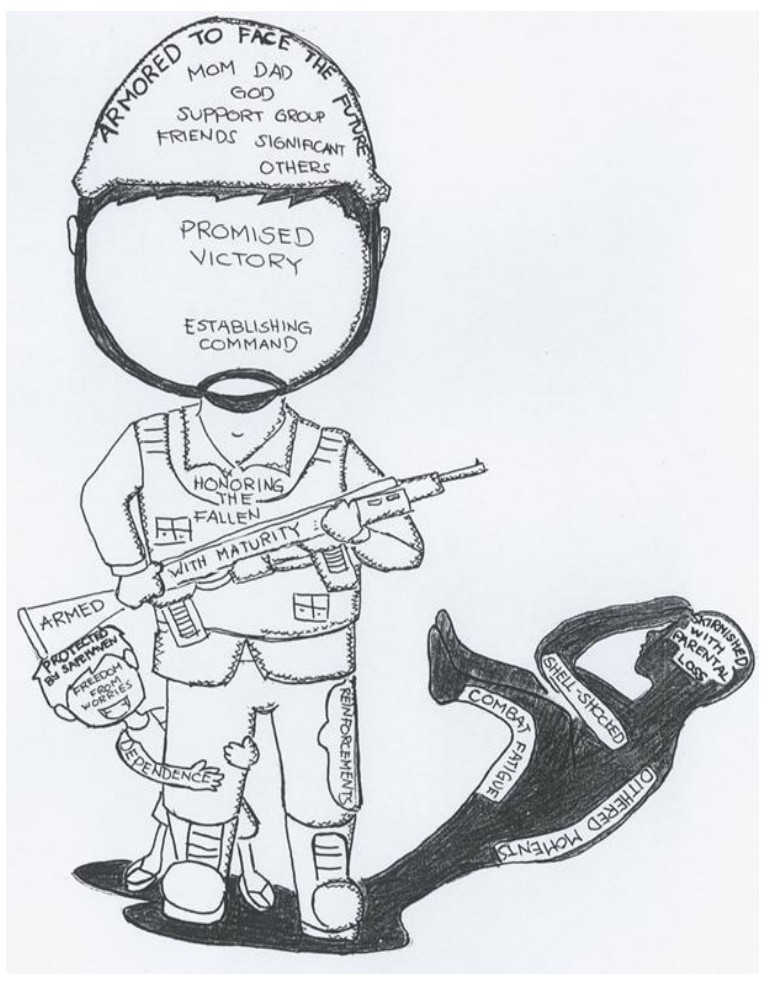

Figure 1. Call of Duty

The participants initially take on a care-free attitude; they live dependently on the parental figure which refers to PROTECTED BY SAFE HAVEN: Being reliant on the parental figure. A child is seen clinging to the soldier. His/her arms represent the pre-death attitude of the eldest child which is DEPENDENCE. He/she would not be able to stand alone if he/she does not hold on to the parental figure. Also, the child's face is seen smiling indicating his mentality that all problems will be solved by the parental figure as shown by FREEDOM FROM WORRIES. This clearly shows the eldest child during those times was vulnerable and highly reliant to the parents.

Subsequently when the unforeseen battle came to their life, SKIRMISHED WITH PARENTAL LOSS occurred, the child being reliant suddenly felt bombarded with the difficult circumstance, illustrated as a shadow forming a fetal position indicating distress as seen on the left side of the soldier. The child experienced variety of emotions, he/she felt SHELL SHOCKED; mixed emotions would come unto him including anger, anxiety, confusion and others. During the fight, he/she 
experienced COMBAT FATIGUE. Knowing that he/she will lose someone important to him/ her, sadness and feeling of weariness amounted into them. Another, he would have DITHERED MOMENTS that makes him/her have doubt in whether continuing fighting or he/she would retreat because if he/she continues fighting he might lose the battle or have himself retreat to avoid the risk to be loss in the battle.

At times of hardship in the battle, the eldest child was able to overcome the psychosocial and emotional obstacles he/she faced during the war and emerged as a triumphant soldier who is now ARMORED TO FACE THE FUTURE characterized by being positive amidst difficulties. The victorious soldier now is armed with maturity that he/she could deal unforeseen battles. Also, he/she is equipped with helmet labelled with the people that reminds him not give up and to continue moving forward. The face of the soldier has no face to be general; PROMISED VICTORY is also indicated in his/her forehead that states the eldest child's mentality after death that good things will happen after the experience, that God has a plan for them, that there is no need to worry. ESTABLISHING COMMAND is also seen in the mouth part indicating that they will be in-charge, that the vacancy that their deceased parent has left will now be their post. On the left upper leg, near the pocket of the soldier lies the word REINFORCEMENTS telling us that in times that the soldier will need help, he/she will have his/her reinforcements at the side of his pocket. And lastly, the word HONORING THE FALLEN on his/her chest which states that the soldier accepts the death, and continues to grow with the experience that helped them blossomed into mature individuals. This phenomenon explains the transformation of a child into a soldier of maturity after experiencing a battle that was unexpected and heeding the "Call of Duty."

Before they encountered this, participants are known to be reliant to the parental figure. They are protected by the safe haven which caused them to be dependent for the essentials of daily living. Assuming the roles and responsibilities of being the eldest in the family was not yet their concern. It is common in the Filipino culture that children are sent to pursue further education until financially independent which explains why the participants are still dependent during the course of the study.

Encountering death is the most important period in which it serves as a turning point in the eldest child's life. Mentioning the word "death" made the participants avoid this topic or be frightened altogether. This is because most people do not discuss this matter, and usually suppresses these types of situations if this had already happened to them in the past (Käpysalo, 2011). The anticipation of death has caused anxiety to the respondent and can be connected to the fear of dying or the lack of knowledge thereof (Bond \& Ens, 2005). The moment the eldest child found out about the diagnosis or the death of his/her parent, a heightened feeling of nervousness and fear within them emerged, leading them to worry and to be doubtful of their state. They seek for rationalizations of why this is happening to them and why does it have to happen at this moment (Delhin \& Reg, 2009). The feeling of exhaustion from this sudden transformation in their life has been very apparent to them. Kübler-Ross (1969) created five phases of grieving which are (1) Denial, (2) Anger, (3) Bargaining, (4) Depression, and (5) Acceptance. When the crisis arises, the person affected undergone the $1^{\text {st }}$ four stages where the feeling of sadness is included (Alexrod, 2006). This unpleasant feeling they experienced bursting out inside of them is part of the normal process of the incident of loss.

Based on the verbatim gathered from this study, the participants find the moment of loss as oppressive because they have already become comfortable with their current living and they expect that their parents will always be with them to wake them up, to cook for them, to provide them with their necessities. At this stage of life, young adults are eager to have their independence and to know their identity to define themselves (Schoonover \& Weiler, 2001) but ironically, they are still reliant on their parents due to that of young adults may discover that they are at a junction between financial and emotional dependence and autonomy (Sachs, 2010). This situation causes them to be anxious about what will happen to their future as their provider has passed away along with the support the parent was giving. Their entry towards their new family duties and obligations, meeting the standard of overmature behavior, and a desire to protect grieving adults may lead them to a feel doubt surrounding themselves (Dowdney, 2008). They are uncertain if they can do their responsibility and whilst justifying society's expectations; because of this situation, anxiety rules over thus leaving them in a state of deciding if they will go on living their life or not.

The period after the death represents the bulk of the phenomena "Call of Duty". After the death of their parent, participants were left by the roles and responsibilities they need to fill in. For this to be 
attained, they needed the presence of the positive influences. It provided them the emotional support they needed for them to be inspired to transcend the difficulties they encounter and will encounter in the future. Through the presence of the support system, it enabled them successful adjustment to loss (Greeff \& Human, 2004). Being accompanied by friends reduces the stress they are experiencing (Smith, Hanson, Norton, \& Hollinghaus, 2013). Furthermore, one of the most helpful communications is the presence of a support in times of need and having the opportunity to express ones feelings and concern (Marwit \& Carusa, 1998). However, according to Dehlin \& Lena (2009) and Walker, Hathcoat, \& Noppe (2012), there are those people who experienced parental death who would not want to seek support from their friends, religion, and family.

Positive emotions are prevalent among the participants, even relatively soon after the loss. Although they were distraught about the death, they perceived this in a positive view in which their parent's sufferings have already ended and thus beginning an everlasting life with God (Engelhardt, 2005). Furthermore, them having this kind of hope that good things will happen after the death of their loved one. Having this faith, despite of difficulty in accepting what happened, comforts them knowing that God has plans for them. This was supported by an article written by Tobin (n.d.), that one who has a religious faith truly believes that God brings good things out of bad events may be very helpful with someone who is undergoing in grieving process. In the end, they continue living even in the absence of their loved one.

Some of them viewed the death experience as a challenge they need to take. It causes an individual to realize that they no longer fit into their old, dependent role, and therefore need to change. Based from the study of Schultz (2007), early maternal loss is a transformative experience for girls that is woven into their developing personalities and thus becomes a defining characteristic of their identities. In fact, the study found that the participants experienced a distinct marker between their past and present selves that may indicate that their mothers' death had broken their sense of continuity of self over time and further raised a feeling of being pushed into adulthood, thus accelerating the normative gradual progression of identity development.

The concept of assuming command was seen also in this study. It pertains to taking charge into the generational position previously held by their parents. It is where they assume the parental roles and responsibilities. According to the online article published by winterspring.org (n.d), when a parent dies, adults view themselves as the "older generation." This oldness brings with it new responsibilities, that of presiding over the younger generation, and reconciling themselves to meeting death head-on with no intermediary. Assuming roles was found in the participants who lost their parent from illness. They assumed leadership of the household through the support and guidance of extended family members which served as their primary support group (Aiyeko 2003). Likewise in the same study by Aiyeko (2003), there were a percentage of the participants who assumed the leadership role by themselves without being prodded into the role.

Lastly, the participants have learned from the death experience. A study by Balk (1983) about bereaved adolescents reported psychological growth evidenced in increased maturity, improvement in academics, higher moral values, and a more mature attitude. Another study by Forward and Garlie (2003) reported that bereaved adolescents reported positive changes including a) more maturity, b) deeper appreciation for life/living life to its fullest, c) taking less risks and assuming a greater purpose for their life.

\section{CONCLuSion}

In summary, the essence of the eldest childs' responses reflected the phenomenon "Call of Duty", captured on a military theme that described their lived experiences towards parental death and specifically highlighted the emotional and psychosocial facets of their experiences. The participants battle their way through the 3 themes "Protected by the Safe Haven" "Skirmished with Parental Loss" and finally "Armored to Face the Future" to achieve the end goal which is maturity. These themes and their subthemes connote the participants' struggles towards maturity from dependence of the parental figure.

\section{RECOMMENDATIONS}

Upon the completion of this study, the researchers have come up with the following suggestions for nursing practice, nursing education, and nursing research. 
Nursing Practice:

As this study gathered the emotional and psychosocial experiences eldest children towards the death of the parental figure, a holistic approach should be conducted to further understand their needs. Furthermore, ethnography should be taken into consideration to be able to offer an appropriate and well-timed support by the nurses and other health care professionals since culture influences the coping of a person.

\section{Nursing Education:}

Professors in the nursing academe can further emphasize on the psychosocial effects of loss since it correlates to the person's coping when crisis arises, and emphasis on the interventions needed not only for the client but also by their support system. Moreover, this will equip student nurses a background about the different effects and coping strategies towards loss. This could also create a sense of appreciation of providing holistic care.

\section{Nursing Research:}

After knowing the emotional and psychosocial lived experiences of eldest children towards parental loss, future research being conducted with a similar study should consider younger participants. The study should have a more specific inclusion criteria such as limiting participants to a single program in a particular year level, the cause of parental death should consider how it occurred and the type of family structure. In addition, the researchers may also focus on gender-specific responses.

\section{LiMitaTiONS}

A descriptive phenomenological approach was utilized in this study. The sample size is based on the saturation point of 5 participants with similar responses to ascertain dependability of data and the credibility of the study. To ensure a homogenous target population, participants were chosen based on the eligibility criteria set by the researchers: The parent (mother or father) has been deceased for 6 months to 3 years, regardless of its nature, the eldest child aged 18-21 years old, who has passed their respective university's psychological test and is currently enrolled at any college level as to promote diversity.

The criterion for recruitment was limited to students who are currently enrolled in their respective universities, this will not take into account the year level the participant is currently in, the cause of parental death, and type of family (nuclear, extended or single-parent) the participants have, as these extraneous factors only increase the difficulty in recruitment of participants and data gathering. Lastly, the researchers being novices in conducting qualitative researches would require more time and resources for the completion of this study.

\section{ACKNOWLEDGEMENT}

We express our deepest gratitude to the following persons who have helped us in making this thesis paper possible.

To our thesis adviser, Asst. Prof. Marica G. Estrada RN, MAN, PhD, who have instilled us the necessary knowledge in order for us to formulate and come about with our thesis paper and who was very diligent in improving our paper.

To Mr. Dennis Cuadra, RN, MAN, who enlightened and strengthen us with positivity and esteem when we are at the point of giving up.

To Mr. Beryl P. Battad RN, MAN, Ms. Jocelyn A. Amongo, Med, and Mr. Edmund Ronald M. Wines RN, MSN, who have validated our tool and added essential points for the improvement of the paper and interview guide.

To our dear parents who were very supportive of all the endeavors that we encountered throughout the whole process and for understanding all the sleep overs that we have conducted in order to improve and finish our paper.

And lastly, to our Almighty God who have showered us with His unending grace, wisdom and strength to succeed amidst all difficulties that we have stumbled upon. 


\section{REFERENCES}

Andrew, C. (1998). Optimizing the human experience: Nursing the families of people who die in intensive care. Intensive \& Critical Care Nursing, 14(2), 59-65.

Aries, P. (1981). The hour of our death: The classic history of Western attitudes toward death over the last one thousand years (2nd ed.). New York: Alfred A. Knopf, Inc.

Axelrod, J. (2006). The 5 Stages of Loss and Grief. Psych Central. Retrieved from http://psychcentral.com/lib/the-5-stages-of-loss-and-grief/000617

Bawalan, R. (2012). Qualitative research: Phenomenology. Retrieved from http://www.slideshare.net/RalphBawalan/qualitative-research-phenomenology

Bolton, J., Au, W., Leslie, W., Martens, P., Enns, M., Roos, L., et al. (2013). Parents bereaved by offspring suicide: A population-based longitudinal case-control study. JAMA Psychiatry, 70(2), 158-167.

Bond, J., \& Ens, C. (2005). Death anxiety and personal growth in adolescents experiencing the death of a grandparent. Death Studies, 171-178. DOI: 10.1080/07481180590906192

Brown, B., \& Jekielek, S. (2005). The transition to adulthood: Characteristics of young adults ages 18 to 24 in America. Census 2000, 1-33.

Burns, N., \& Groves, S. (2013). Burns \& Grove's understanding nursing research. Singapore: Elsevier Saunders.

Chen, C., Kuo, C., Wu, T., \& Yang, C. (2012). Death of a son is associated with risk of suicide among parous women in Taiwan: A nested case-control study. Journal of Epidemiology, 22(6), 532-536.

Corn, B. W. (2009, December 31). Ending end-of-of-life phobia -- A prescription for enlightened health care reform. The New England Journal of Medicine, 63(27), 361.

Creswell, J. (2009). Research design: Qualitative, quantitative, and mixed methods approaches. Los Angeles: Sage.

Dehlin, L., \& Reg, L. (2009). Adolescents' experiences of a parent's serious illness and death. Palliative and Supportive Care, 7(1), 13-25.

Dowdney, L. (2008). Children bereaved by parent or sibling death. Psychiatry, 7(6), 270-275.

Engelhardt, H. J., \& Iltis, A. (2005). End-of-life: the traditional Christian view. The Lancet, 10451049.

Fletcher, P. N. (2002, April). Experiences in family bereavement. Family Community Health, 25(1), 57-70.

Fridh, I., Forsberg, A., \& Bergbom, I. (2009). Doing one's utmost: Nurses' descriptions of caring for dying patients in an intensive care environment. Intensive Critical Care Nursing, 25(5), 233-241.

Greeff, A. P., \& Human, B. (2004). Resilience in families in which a parent has died. American Journal of Family Therapy, 32(1), 27-42.

Groenewald, T. (2004). A phenomenological research design illustrated. International Journal of Qualitative Methods, 3(1), 5.

Käpysalo, K. (2011). How to ethically investigate adolescents' conceptions of death and death anxiety? Retrieved from http://blogs.helsinki.fi/kapys.../.../2011/01/Ethically-2011.pdf

Bostrom, C., Keltner, N., \& Schwecke, L. (2007). Psychiatric Nursing Fifth Edition. Singapore: Mosby Elsevier.

Kliegman, R. M., Stanton, B. M., St. Geme, J., Schor, N., \& Behrman, R. E. (2011). Nelson Textbook of Pediatrics. Philadelphia, PA: Saunders Elsevier.

Kübler-Ross, E. (1969). On Death and Dying. Simon and Schuster

Li, J., Johansen, C., Hansen, D., \& Olsen, J. (2002). Cancer incidence in parents who lost a child: A nationwide study in Denmark. Cancer, 95(10), 2237-2242.

Li, J., Johansen, C., \& Olsen, J. (2003). Cancer survival in parents who lost a child: A nationwide study in Denmark. British Journal of Cancer, 88(11), 1698-1701.

Li, J., Laursen, T., Precht, D., Olsen, J., \& Mortensen, P. (2005, March 24). Hospitalization for mental illness among parents after the death of a child. The New England Journal of Medicine, 352(12), 1190-1196. 
Manson, M. (2010). Forum: Qualitative Social Research. Sample size and saturation in $\mathrm{PhD}$ studies using qualitative interviews, 11(3).

Marlowe, D. (2000). Psychological and psychosocial consequences of combat and deployment with special emphasis on the Gulf War. Retrieved fromhttp://www.gulflink.osd.mil/library/randrep/ marlowe_paper/

Marwit, S. J., \& Carusa, S. S. (1998). Communicated support following loss: Examining the experiences of parental death and parental divorce in adolescence. Death Studies, 237-255.

Merriam-webster dictionary. (2014). Massachusetts: Merriam-Webster, Inc.

Moustakas, C. (1994). Phenomenological research methods. Thousand Oaks, CA: SAGE Publications.

Murphy, S., Tapper, V., Johnson, L., \& Lohan, J. (2003). Suicide ideation among parents bereaved by the violent deaths of their children. Issues in Mental Health Nursing, 24(1), 5-25.

Najman, J., Vance, J., Boyle, F., Embleton, G., Foster, B., \& Thearle, J. (1993). The impact of a child death on marital adjustment. Social Science and Medicine, 37(8), 1005-1010.

Nazarene Organization. (2013). What is a young adult? Retrieved from http://nazarene.org/files/docs/ young\%20adult-2.pdf

Oliver, P. (2006). Purposive sampling. Sage Journals. DOI: 10.4135/9780857020116

Polit, D. F., \& Beck, C. T. (2008). Nursing research principles and methods. Lippincott Williams \& Wilkins.

Price, J., Jordan, J., Prior, L., \& J., P. (2011). Living through the death of a child: A qualitative study of bereaved parents' experiences. International Journal of Nursing Studies, 48(11), 1384-1392.

Rogers, C. H., Floyd, F. J., Seltzer, M. M., Greenberg, J., \& Hong, J. (2008). Long-term effects of death of a child on parent's adjustment in midlife. Journal of Family Psychology, 22(2), 203-211.

Rossman, R., \& Rallis, S. (1998). Learning in the field: An introduction to qualitative research. Thousand Oaks, CA: Sage.

Rostila, M., Saarela, J., \& Kawachi, I. (2012). Mortality in parents following the death of a child: A nationwide follow-up study from Sweden. Journal of Epidemiology and Community Health, 66(10), 927-933.

Sachs, B. (2010). Emptying the Nest: Launching Young Adults toward Success and Self-Reliance. New Hampshire, England: Palgrave Macmillan Trade.

Sanders, C. M. (1979). A comparison of adult bereavement in the death of a spouse, child, and parent. OMEGA--Journal of Death and Dying, 10(4), 303-322.

Schoonover, S., \& Weiler, N. (2001). Life stages and career planning. Your Soul at Work. Retrieved from http://www.yoursoulatwork.com/life_stagestm

Schultz, L. (2007). The influence of maternal loss on young women's experience of identity development in emerging adulthood. Death Studies, 31(1), 17-43.

Schwandt, T. (2000). Three epistemological stances for qualitative inquiry: Interpretivism, hermeneutics, and social construction. In N. K. Denzin \& Y. S. Lincoln, (Eds.), Handbook of qualitative research (pp. 189- 213). Thousand Oaks, CA: Sage.

Shosha, G. (2012). Employment of colaizzi's strategy in decriptive phenomenology: A reflection of a researcher. European Scientific Journal, 31-43.

Simkin, J. (1997, 2014). First world war encyclopedia. England: Spartacus Educational.

Smith, K. R., Hanson, H. A., Norton, M. C., \& Hollinghaus, M. S. (2013). Surviving offspring who experience early parental death: Early life conditions and later-life mortality. Social Science and Medicine, 1-11.

Tobin, E. (n.d.). Dealing with the loss of a loved one. Retrieved from http://www.ascensioncatholic.net/misc-writings/ dealing-with-the-loss-of-a-loved-one/

Walker, A. C., Hathcoat, J. D., \& Noppe, I. C. (2012). College student bereavement experience in a Christian University. Omega, 241-259.

Waters, J. (2014). Phenomenological research guidelines. Retrieved from https://www.capilanou.ca/ psychology/ student-resources/research-guidelines/Phenomenological-Research-Guidelines/ 
Winterspring.org. (n.d.). For adults who have lost a parent. Retrieved from http://winterspring.org/wp content/uploads/2012/10/102470205-Adult-Parent-Loss.pdfVaezzadeh, N., Douki, Z.E, Hadipour, A., Osia, S., Shahmohammadi, S., and Sadeghi, R. (2011). The effect of performing preoperative preparation program on school age children's anxiety. Iranian Journal of Pediatrics, Vol. 21 (4), pp. $461-466$.

Wollin, S., Plummer, J.L., Owen, H., Hawkins, R.M.F., Materazzo, F., and Morrison, V. (2004). Anxiety in children having elective surgery. Journal of Pediatric Nursing, Vol. 19, pp. $128-$ 132. 